\title{
KAFALA Y DERECHO ESPAÑOL TRAS LA REFORMA DE LA LEY 54/2007. A PROPÓSITO DEL AUTO AP DE LEÓN DE 27 DE JUNIO DE 2019
}

\author{
KAFALA AND SPANISH LAW AFTER REFORM OF THE LAW \\ 54/2007. ON THE AUTO AP LEÓN OF 27TH JUNE 2019
}

\author{
MÓNICA GuZMÁn ZAPATER \\ Catedrática de Derecho internacional privado \\ UNED \\ Recibido: 15.04.2020 / Aceptado: 04.05.2020 \\ DOI: https://doi.org/10.20318/cdt.2020.5651
}

\begin{abstract}
Resumen: No reconocimiento de Kafala constituida entre ciudadanos marroquíes a efectos de adopción. Antecedentes y alcance de la prohibición contenida en el artículo 19.4 de la Ley de adopción internacional. La prohibición de constitución de adopción frente a ley personal del menor prohibitiva está dirigida a las autoridades competentes y su infracción, fuera de las excepciones previstas, invalida la adopción.
\end{abstract}

Palabras clave: kafala, reconocimiento, adopción internacional, ley personal del menor prohibitiva.

Abstract: Non recognition of kafala between moroquians citizens as basis to constitute international adoption. Legal framework and Prohibition in Artícle 19.4 International Adoption Law in order to avoid international adoptions wether personal law forbids such a mesure, it's directly adressed to authorities and just legal exceptions should be admitted.

Keywords: kafala, recognition, adoption, prohibition in minor's personal law.

Sumario: I. Introducción. II. Los efectos de la kafala y su tratamiento jurídico. III. El caso planteado en el contexto vigente. 1. Sobre la posibilidad de constituir en España una adopción respecto de una menor sometida a Kafala en Marruecos. 2. Sobre la posibilidad de constituir un acogimiento familiar permanente.

\section{Introducción}

1.La proximidad geográfica con Marruecos y el hecho de que sus nacionales resulten ser el colectivo de inmigrantes con más amplia presencia en España explica la repetición de supuestos objeto de este comentario al Auto AP de León n ${ }^{\circ}$ 57/2019, de 27 de junio 2019¹. La parte demandante recurría el Auto dictado por el Juzgado de $1^{\mathrm{a}}$ Instancia de León, de 14 de septiembre de 2018, por el que se denegaba el reconocimiento de efectos a una Kafala constituida en Marruecos a los fines de la constitución de una adopción planteada por una nacional marroquí sobre una menor de la misma nacionalidad, por entender que el consentimiento se había dado a una institución distinta de la adopción; y, subsidiaria-

${ }^{1}$ CLI: ES: APLE: 2019:922A 
mente se solicitaba que, de no ser autorizada la adopción se permitiera un acogimiento familiar permanente, pretensión también denegada. Y pese a que el Ministerio Fiscal recomendase la desestimación del recurso sobre el Auto de primera instancia, la Audiencia Provincial de León confirma el Auto en el punto de desestimar la posibilidad de constitución de la adopción sobre la menor y autoriza en cambio un acogimiento familiar permanente, con un buen criterio y sólida argumentación.

2. El sustrato fáctico es pues bastante habitual y viene a reproducir un problema deja $v u$ en distintas instancias judiciales. Reafirma la idea de la falta de analogía entre la kafala y la adopción al no crear un vínculo de filiación ${ }^{2}$. El problema no es tanto el reconocimiento como tal de la institución, extraña a nuestro ordenamiento pero admitida por la Convención de NU sobre los Derechos del niño de 1989 (art. 20.3) y por tanto en principio compatible como tal con nuestro orden público. El problema reside en el reconocimiento de sus efectos, incompatibles con la adopción y únicamente reconducibles a la tutela o al acogimiento familiar permanente al reproducir éste el contenido personal de la patria potestad (art. 173 $\mathrm{CC}$ ), esto es, la obligación de velar por él, tenerlo en su compañía, alimentarlo, educarlo y procurarle una formación integral. Estos son los términos del problema planteado en el caso objeto de este comentario. La resolución judicial se enmarca correctamente en la prohibición contenida en el artículo 19.4 de la Ley de adopción internacional (LAI), norma ésta resultante de un proceso de evolución lento pero firme en nuestro derecho positivo, al que en ocasiones no se aviene la jurisprudencia de los tribunales.

\section{Los efectos de la kafala y su tratamiento jurídico}

3. Para valorar la solución cualquier toma de posición exige examinar someramente el marco jurídico para el reconocimiento de efectos civiles y la consideración de la kafala constituida en el extranjero ${ }^{3}$.

4. $\left.1^{\circ}\right)$ En primer lugar conviene recordar que la kafala y la cuestión del reconocimiento de sus efectos civiles está presente en los instrumentos internacionales más relevantes. La propia Convención de Naciones Unidas sobre los Derechos del Niño de 1989 recoge en su artículo 20.3 la institución de la Kafala. Asimismo el Convenio de La Haya de 19 de octubre de 1996, relativo a la competencia, la ley aplicable, el reconocimiento, la ejecución y la cooperación en materia de responsabilidad parental y medidas de protección de los niños ${ }^{4}$ incluye de forma expresa la kafala (art. 3.c) CLH 1996) y garantiza que la decisión de trasladar de país de residencia al menor objeto de kafala sea adoptada por autoridad competente y con la aprobación de la autoridad del Estado de origen art. 3.c) en relación con art. 1 CLH 1996). La garantía se extiende a asegurar el reconocimiento de la kafala en los Estados parte del Convenio, como medida de protección dentro del ámbito material, si bien dentro de los límites del orden público del Estado requerido teniendo en cuenta el interés superior del niño (art. 23.2.c) CLH).

\footnotetext{
${ }^{2}$ Como tampoco es idéntica a la tutela. Es una institución de protección de menores singular. Entre nosotros su examen desde la perspectiva de buscar la equivalencia con las CATEGORÍAs previstas en nuestro ordenamiento destacan los trabajos de P. Diago Diago "La Kafala islámica en España”, Cuadernos de Derecho Transnacional, Vol. 2, (Marzo 2010) No 1, pp. 140-164, (www.uc3m.es/cdt), espec. pp. 152-158; A. RodRíGUEz BENOR "Adopción y kafala: un análisis de su alcance respectivo en los ordenamientos occidentales", Derecho internacional y relaciones internacionales en el Mundo Mediterráneo (Actas de las XVII Jornadas de la AEPDIRI), Madrid, BOE, 1999, pp. 195-206.

${ }^{3}$ Dejamos a un lado la cuestión de los efectos administrativos. El reconocimiento de efectos administrativos la kafala constituida en el extranjero ha dado lugar a cuestiones más concretas en la jurisprudencia contencioso-administrativa: si sirve de fundamento del derecho a percibir una pensión de la Seguridad social (STS de Madrid, Sala de lo Social, de 31 de enero (JUR 2008/146505), vid.. S. GARCía CANo, "Nota", REDI 2008, 1, pp. 254-256.; si la Kafala constituida atribuye la representación legal del menor a los efectos de obtener visado por reagrupación, en Sentencia TSJ de Madrid, Sala de lo Contencioso, de 3 de abril 2008 (JUR 2008/189480) (vid. N. Marchal Escolona "Nota”, REDI, 2008, 2, pp. 606-609). Sobre la dimensión de extranjería vid. S. ADROHER BIOSCA "La kafala islámica: Medida de protección de menores o estrategia migratoria?", Revista de Derecho migratorio y extranjería, 45, pp. 203-220 espe. pp. 216 ss.; M. VARGAS URrutia, "La kafala del Derecho musulmán y el Tribunal Supremo", El Tribunal Supremo y el Derecho internacional privado. Vol. 2. (A. L. CAlvo CARAVACA / J. CARRASCOSA GonZÁlez, Dirs), Colección Derecho y Letras, núm. 1, Murcia, 2019, p. 475-488.

${ }^{4} B O E \mathrm{n}^{\circ} 291$, de 2 de diciembre 2010
} 
5. Esta misma cuestión del reconocimiento de los efectos de una kafala constituida sobre menor argelino en el extranjero a los fines de conversión en adopción está en la base de la STEDH de 4 de octubre de 2012, recurso $n^{\circ} 43631 / 2009$, Harroudj c.Francia ${ }^{5}$, en cuyo sustrato fáctico consta que se pretendía que la kafala constituida en el extranjero produjera en el Estado de acogida efectos equivalentes a la adopción (plena) basándose principalmente en el derecho fundamental del menor a una vida privada y familiar, que se vería afectado por la prohibición de adopción de una menor cuando su ley nacional lo impide, contenida en el Código civil francés (salvo que el menor haya nacido y posea residencia habitual en Francia). La demandante recurre al TEDH para que see pronuncie sobre si la norma francesa suponía una infracción, por una parte, del principio de no discriminación (art. $14 \mathrm{CEDH}$ ) y por otra, si vulneraba el derecho al respeto a la vida privada y familiar $(e x . \text { art. } 8 \mathrm{CEDH})^{6}$. El TEDH, establece en primer lugar, que la kafala no produce un vínculo de filiación ${ }^{7}$ y añade que no constituye una infracción del derecho a la vida privada y familiar y tampoco es lesiva del derecho a la continuidad de una relación pseudo-familiar. El Tribunal entiende que la kafala es una medida de protección que coexiste con otras en el estado de acogida.

6. Y por último, en tiempos recientes el TJ de la Unión Europea se ha pronunciado en Sentencia de 26 de marzo de 2019, en el asunto C-129/18, al interpretar en el marco del recurso prejudicial el concepto de "descendiente directo" que figura en el artículo 2.2 c) de la Directiva 2004/38 del Parlamento Europeo y del Consejo, de 29 de abril de 2004, relativa a la libre circulación de los ciudadanos de la Unión y de los miembros de sus familias; fallando en sentido negativo al afirmar que dicho derecho no incluye a una menor que se halla bajo tutela legal permanente de un ciudadano de la Unión con arreglo a la institución de la kafala argelina puesto que dicho régimen no crea un vínculo de filiación entre ellos ${ }^{8}$.

7. $2^{\circ}$ ) En el ordenamiento español nótese que hasta la entrada en vigor de la LAI 54/2007, el reconocimiento de la kafala como adopción fue habitual, dado que el artículo $9.5 \mathrm{Cc}$ permitía descartar la aplicación de la ley nacional del adoptando (en lo relativo a su capacidad y los consentimientos necesarios para la adopción) si éste adquiría la nacionalidad española por la adopción y si el adoptante tenía la nacionalidad española.

8. En este contexto la Dirección General de los Registros y del Notariado, por Resolución Circular de 15 de julio de 2006 sobre reconocimiento e inscripción en el Registro español de adopciones internacionales 9 , sentó las bases para la calificación de esta institución extranjera al afirmar que "La kafala...no crea un vínculo de filiación...", si bien la caracteriza como similar a un acogimiento familiar en cualquiera de sus modalidades (simple o permanente) recogido en el artículo 173 bis Cc, bien como tutela. Se admitieron ciertos efectos con la condición de no vulnerar el orden público español y la presentación de documentos debidamente legalizados y traducidos. Se excluye desde entonces que la kafala pueda ser reconocida como una adopción ${ }^{10}$.

\footnotetext{
${ }^{5}$ STEDH (Sala 5a) de 8 de octubre 2012. Vid. C.I. Cordero Álvarez, "Nota", REDI, 2013 (2), pp. 284-287, p. 286.

${ }^{6}$ Con anterioridad la infracción de dichos derechos como consecuencia del no reconocimiento en Grecia de una adopción constituida en EEUU, fue contrastada en la STEDH de 3 de mayo 2011, $\mathrm{n}^{\mathrm{o}}$ 56759/08, Negrepontis c. Grecia. Vid. C.I. CORDERO Álvarez "Adopción en Europa y efectos de la kafala en el marco del Convenio Europeo de Derechos humanos", AEDIPR, t. XII, 2012, pp. 455-489.

${ }^{7}$ Cf. C.I. Cordero Álvarez "Nota", cit.. p. 286.

${ }^{8}$ Para dar una respuesta al problema planteado y permitir el ejercicio efectivo de la libre circulación al pseudo-familiar del titular del kafala, el TJ añade una matización a mi parecer controvertida : "Si bien, en caso de que se demuestre que en circunstancias normales, la menor y su tutor (que es ciudadano de la Unión), llevaran una vida familiar efectiva y que la menor depende de su tutor, las exigencias vinculadas al derecho fundamental a la vida familiar, junto con la obligación de tener en cuenta el interés superior del menor, en principio requerirán que se otorgue a ésta el derecho de entrada y residencia al objeto de permitir que viva con su tutor en el Estado miembro de acogida de éste".

${ }^{9}$ Res Circular de 15 de julio de 2006 sobre reconocimiento e inscripción en el Registro Civil español de las adopciones internacionales (BOE núm. 207, de 30 de agosto de 2006).

${ }^{10} \mathrm{Si}$ bien se ha destacado que en esa misma Resolución Circular se apelaba a que las autoridades implicadas descendieran al análisis caso por caso (vid. A. LARA AGUADo“Adopción internacional: Relatividad de la equivalencia de efectos y sentido común en la interpretación del derecho extranjero” REDI, 2008,1, pp. 129-145).
} 
9. $3^{\circ}$ ) Pues bien, con la LAI 54/2007 de 28 de diciembre, sobre Adopción internacional, se avanza en la interpretación de la DGRN al elevar a derecho positivo y establecer la asimilación de la kafala con el acogimiento familiar o con la tutela para aquellas instituciones de protección de menores constituidas ante autoridades extranjeras que no produzcan efectos de filiación cuando cumplan los requisitos del artículo 34.1 LAI 2007: "Las instituciones de protección de menores constituidas por autoridad extranjera y que, según la ley de su constitución, no determinen ningún vínculo de filiación se equipararán al acogimiento familiar o, en su caso, a una tutela, regulados en el derecho español". Desde entonces es meridianamente claro que no cabe utilizar el mecanismo de conversión para las adopciones simples o menos plenas constituidas en el extranjero en adopciones plenas previsto por la LAI 2007.

10. $4^{\circ}$ ) En la línea de matizar el problema que planteaba constituir adopciones cuando la ley nacional del adoptando prohibía o desconocía la adopción, se admitían matices para supuestos que presentan lo que se ha denominado la "conexión social" al estar el adoptando ya integrado en nuestro país $^{11}$, asimismo acogidos en la Circular 8/2011 sobre criterios para la unidad de actuación especializada del Ministerio Fiscal en materia de protección de menores, si el adoptante ostentaba la nacionalidad española y el menor residía en España aunque la ley nacional lo prohibiera ${ }^{12}$.

11. $5^{\circ}$ ) En buena medida parece que la jurisprudencia ha sido fiel a los criterios de calificación establecidos por la DGRN en su Resolución Circular de $2006^{13}$. En la práctica los problemas que se han venido planteando han sido dos. Por una parte, la mencionada cuestión del reconocimiento de efectos de esta institución desconocida en nuestro ordenamiento y generalmente declarada como equivalente a un acogimiento preadoptivo firme ${ }^{14}$. En ocasiones la jurisprudencia ha sido flexible hacia supuestos de kafala cuya conversión en adopción tuvo lugar en el exterior y por tanto admisible vía reconocimiento de la adopción ${ }^{15}$.

Por otra parte, incluso con anterioridad a la reforma de 2015, la equiparación funcional de la $\mathrm{ka}$ fala al acogimiento o tutela españoles, constituía una antesala que facilitaba la constitución ex novo de la adopción ${ }^{16}$. En esos supuestos la práctica judicial ha sido mucho más vacilante y por tanto equívoca, en lo relativo a la exigencia o no de certificado de idoneidad para la constitución de adopciones, dado que al haber sido asimilada la kafala a una guarda o tutela se allanaba el camino a la adopción evitando la propuesta previa. Uno se encuentra con decisiones judiciales que no exigen el certificado de idoneidad, en unos casos por entender cumplido o transcurrido un año de acogimiento no debía de exigirse propuesta previa, resolviendo que “... se permite la petición directa de los adoptandos sin perjuicio de que en estos casos, como en los demás, debe de valorarse por el Juez las condiciones de idoneidad de los adoptantes o adoptando". En cambio, sí se ha exigido y por tanto se deniega la constitución de la adopción en otros casos, pues sobre la base de la equiparación entre kafala y acogimiento que la DGRN había formulado en su Resolución Circular de 2006, se determina que “...esta equiparación no permite prescindir de la actuación de las autoridades estatales...”17, es decir, de la tramitación del expediente de idoneidad.

11 Cf. A.L. Calvo Caravaca / J. Carrascosa González, La Ley 54/2007 de 28 de diciembre 2007 sobre adopción internacional (Reflexiones y comentarios), Comares, Granada, 2008, p. 118.

${ }_{12}$ Sobre esta cuestión vid. E. Rodríguez Pineau, "La protección en España de menores cuya ley nacional prohíbe la adopción tras la reforma de la Ley 54/2007, de Adopción internacional” Derecho Privado y Constitución, 31, 387-415. DOI: https://doi.org/https://doi.org/10.18042/cepc/dpc.31.09, pp. 398-399.

${ }^{13}$ Así se pone de relieve a partir de un análisis amplio de la jurisprudencia desarrollado por P. JuÁrez Pérez, "La Kafala islámica como institución de protección: interpretación y práctica españolas", en Protección de menores y Derecho internacional privado (A.Cebrián SALVAt./I.Lorente Martínez, dirs.), ed. Comares, Granada, 2019 pp.143-171, espec. pp.151-152.

${ }^{14}$ Así, Auto AP de Gerona, Sección primera, de 18 diciembre 2017 (ECLI:ES: APGI:2017:1116 A).

15 Así en ejemplar Res DGRN (18) de 17 de febrero 2014 (BIMJ, Resoluciones DGRN, 9 de julio 2015, pp. 7-9), N. Marchal Escalona, "Denegación del reconocimiento y la inscripción en el registro civil español de una adopción constituida en el extranjero", AEDIPr, 2014-2015, pp. 1223 y ss.

16 Cf. A.L. Calvo Caravaca / J. Carrascosa González, La ley 54/2007, de 28 de diciembre 2007 sobre adopción internacional...cit. p. 316; P. Juarez Perez, "La kafala islámica...", cit. p. 153. Subyace en Sentencia TSJ de Madrid, Sala de lo Contencioso, de 3 de abril 2008 (JUR 2008/189480) en la que el problema central era determinar si la Kafala constituida atribuye la representación legal del menor (vid. N. Marchal EsCALona, "Nota”, REDI, 2008, 2, pp. 606-609).

${ }_{17}$ AP de Tarragona (Sección $1^{\text {a }}$ ) Auto de 23 de junio de 2008. Recientemente, en el mismo sentido, Auto AP Barcelona, Sección decimoctava, de 28 de mayo 2019. 
12. En fin, un marco jurídico desordenado por la práctica, conducente a situaciones desiguales dentro del ámbito español y a la postre, generador situaciones claudicantes en orden a alcanzar el reconocimiento en el país de la nacionalidad del menor adoptado en su país de origen, son los datos que alertaban acerca de un problema real y hasta cierto punto explican la intervención del legislador en 2015, como se verá.

13. $6^{\circ}$ ) La Ley 26/2015, de 28 de julio, que modifica el sistema de protección de la infancia y de la adolescencia, añade un nuevo párrafo, apartado 4 en el artículo 19 LAI 2007, conforme al cual "En el caso de menores cuya ley nacional prohíba o no contemple la adopción se denegará la constitución de la adopción, excepto cuando el menor se encuentre en situación de desamparo y tutelado por Entidad Pública"18. Desde entonces se levanta esta prohibición de constitución de la adopción (“...se denegará la constitución...) respecto de menores cuya ley nacional desconozca o prohíba la adopción. La prohibición es terminante: no diferencia entre menores residentes en su país de origen o menores trasladados y residentes en España por adoptantes españoles. En conjunto la doctrina ha acogido este precepto de modo desigual ${ }^{19}$.

14. Únicamente se prevé una excepción legal expresa en cuanto al menor abandonado y tutelado por Entidad pública (art. 19.4 in fine) y la norma deja abierto un resquicio. En efecto, dado que el ámbito de aplicación personal del precepto se circunscribe a los menores de edad (como no podía ser de otro modo dado que la LAI 2007 se aplica a los menores de 18 años, en correspondencia con el Convenio de La Haya de 1993 sobre Adopción), cabe la posibilidad (o la duda) de interpretar que dicha prohibición no se proyecta sobre adoptandos mayores y menores emancipados, que pueden ser adoptados conforme a lo previsto en el artículo 175. 2. c) Cc. Y si bien la adopción de menores emancipados y sobre todo de mayores, son supuestos controvertidos dada la caracterización contemporánea de la adopción como medida de protección de menores y desde esa perspectiva se ha planteado la no aplicabilidad de la LAI 2007, no faltan autores que admiten que está dentro de su ámbito dada la ausencia de una exclusión expresa, planteamiento que compartimos ${ }^{20}$.

15. Finalmente, desde otras instancias orientadas a dar respuesta a los persistentes supuestos de traslado por españoles a nuestro país de menores en situación de kafala, se ha mantenido el criterio restrictivo incluso para los supuestos en que, como éste, ofrecen una cierta "conexión social" con nuestro país. Así, en el Dictamen 3/2016 sobre incidencia de la reforma de la Ley 54/2007, de 28 de diciembre de Adopción internacional ${ }^{21}$, respecto al tratamiento de la kafala se afirma que: $1^{\circ}$ ) debe constatarse suficientemente que la legislación nacional del adoptando prohíbe o no contempla la adopción; $2^{\circ}$ ) que el menor no adquiera la nacionalidad española en virtud de la adopción y por tanto mantiene la suya; $3^{\circ}$ ) indica que la restricción no opera en los supuestos en que el menor se halle en situación de desamparo y tutelado por Entidad pública.

La adquisición de la nacionalidad española puede resultar de haber estado sujeto el menor a acogimiento por persona o institución española durante dos años consecutivos (art. 22.2.c) Cc), quedando descartada la práctica anterior conforme a la cual se reconocía una conexión anticipada a la nacionalidad

\footnotetext{
${ }^{18}$ Sobre esta nueva disposición y sus antecedentes S. Adroher Biosca "La kafala islámica: Medida de protección de menores o estrategia migratoria?", Revista de Derecho migratorio y extranjería, 45, pp. 203-220; E. RodríGuEz Pineau, "La protección en España de menores cuya ley nacional prohíbe la adopción tras la reforma de la Ley 54/2007, de Adopción internacional" Derecho Privado y Constitución, 31, 387-415. DOI: https://doi.org/https://doi.org/10.18042/cepc/dpc.31.09; M.J.SÁnchez CAno, "Adopción en España de menores en situación de Kafala y ley nacional del adoptando", Cuadernos de Derecho transnacional (Octubre 2018), Vol. 10, No 2, pp. 931-946 (www.uc3m.es/cdt).

${ }^{19}$ Conforme, pues impedirá las adopciones fraudulentas ( $c f$. A. DuRÁn AYAGO, "Aspectos internacionales de la reforma del sistema de protección de menores. Especial referencia a la adopción internacional”, AEDIPr, t. XVI, 2016, p. 444); más escéptica, M.J. SÁnchez CANo, “Adopción en España de menores... “, cit. pp-937-938; a partir de un examen exhaustivo de los antecedentes y crítica desde la perspectiva de la protección del interés del menor E. RodRíGUez PINEAU, "La protección en España de menores cuya ley nacional prohíbe la adopción tras la reforma de la Ley 54/2007, de Adopción internacional" cit. espec. 409-413.

${ }^{20}$ Cf. A.L. Calvo Caravaca / J. Carrascosa González,, La ley 54/2007 de 28 de diciembre 2007 sobre adopción internacional...cit. pp. 43-44.

${ }^{21}$ https://www.fiscal.es/fiscal/PA_WebApp_SGNTJ_NFIS/descarga/Dictamen
} 
española ${ }^{22}$. Esta interpretación permite desbloquear la situación de las kafalas constituidas por españoles para su posterior traslado y constitución de la adopción en España.

\section{El caso planteado en el contexto vigente}

16. Esta nueva disposición (art. 19.4 LAI 2007) cierra el paso a situaciones como las que subyacen en la sentencia objeto de este comentario. Quizás la singularidad que hay que resaltar en este caso es la común nacionalidad (marroquí) del adoptante y la adoptanda dato al que se añade la residencia en España de ambas, alejándose del supuesto más común, el de españoles que acuden o acudían a Marruecos y otros países de tradición islámica, constituían una kafala, desplazaban al menor a España y aquí iniciaban los trámites de constitución en adopción plena.

\section{Sobre la posibilidad de constituir en España una adopción respecto de una menor sometida a Kafala en Marruecos}

17. La primera cuestión que se plantea es si constituida la Kafala en Marruecos, entre nacionales marroquíes residentes en España, cabe reconocer sus efectos a los fines de constituir una adopción ante autoridad española sobre un menor sobre el que ya hay un régimen de kafala. La Audiencia Provincial de León en este caso, después de manifestar $1^{\circ}$ ) la falta de equivalencia de esta institución con el derecho español, $2^{\circ}$ ) de admitir que estas instituciones de protección extranjeras pueden tener efectos en sede de acogimiento familiar o en su caso de tutela, $3^{\circ}$ ) no apreciando situación de desamparo, única excepción posible en sede del artículo 19.2 LAI 2007, 4º toma en cuenta la prohibición del artículo 19.4 LAI 2007 para proyectarla de lleno al caso planteado ${ }^{23}$. A mi entender la respuesta es conforme a los presupuestos del derecho vigente y por tanto correcta.

18. En efecto, la respuesta debe ser terminantemente negativa. El tenor de la norma es meridianamente claro en un punto: contiene una prohibición de constitución de la adopción dirigida a la autoridad inicialmente competente ("se denegará la constitución de la adopción...) cuya infracción por vía de consecuencia debe ser la invalidez de la adopción por falta de competencia en la autoridad interviniente. Basta con que la ley nacional del adoptando desconozca o prohíba la adopción. Se trata de una prohibición sin paliativos. Solo admitiría excepciones en el supuesto legalmente previsto (que el menor se halle en situación de abandono) y en los casos en que adquiera la nacionalidad española, tal y como lo ha interpretado la Fiscalía General en su Dictamen 3/2016. Como excepciones, son de interpretación estricta, y a mi entender debieran haber sido introducidas con una limitación temporal, en orden a resolver los asuntos que estaban pendientes en 2015, pero no como solución general pues no servirá para desincentivar la constitución de kafalas en países con leyes prohibitivas o desconocedoras de la adopción.

19. Estos argumentos tendentes a modular la prohibición no se proyectan en el caso de la Sentencia en análisis porque no se dan los presupuestos fácticos para atenuar la prohibición. Pese a la residencia en España, el menor no adquiere la nacionalidad española por la adopción. Al mantener la nacionalidad marroquí la constitución de la adopción sobre la base de la kafala podría dar lugar a una situación claudicante (p.ej. de haber familiares afectados en Marruecos) dado que la ley nacional del menor (marroquí) coloca el supuesto bajo el ámbito de un ordenamiento que desconoce la adopción. Sin olvidar, por último, que fue precisamente Marruecos el país que suspendió las kafalas durante algún tiempo en un intento de controlar y evitar la salida de menores del país ${ }^{24}$. Y es sabido también que la

\footnotetext{
${ }^{22}$ Vid. E. Rodríguez Pineau, “La protección en España de menores cuya ley nacional prohíbe la adopción...., cit. p.408.

${ }^{23} \mathrm{FJ}^{\circ}$.

${ }^{24}$ Da cuenta de la situación desde la perspectiva marroquí, S. Adroher BiosCA, "La kafala islámica...”, cit. pp. 213-
} 
cuestión alcanza y se proyecta como una sombra sobre la política exterior española, siendo Marruecos un vecino tan próximo como relevante.

20. Esta SAP León destaca y se distancia de otros antecedentes en la jurisprudencia española no tan rigurosos. En efecto, ya en vigor el artículo 19.4 LAI 2007 tras la reforma de 2015, y siendo loable y respetable la opinión del juzgador, en otros supuestos se ha admitido el reconocimiento de la kafala a fines de adopción, sorprendentemente y contra el criterio del Ministerio Fiscal, con argumentos como que “....en el derecho marroquí no están prohibidas las adopciones ...tan solo es una figura o institución que no existe en la Ley, siendo la kafala la institución de máxima protección para los niños abandonados...", concluyendo que "...debe primar la interpretación más favorable para el interés del menor..."25. Y se llega a análogo resultado, en el Auto de la AP de Girona de 18 de diciembre de 2018 por el que se revoca el Auto dictado en primera instancia. Obviando cualquier referencia al artículo 19.4 LAI 2007, se autoriza la adopción de una menor sometida a Kafala sobre la base de la positiva integración de la menor en la familia adoptante ${ }^{26}$, posición que como ya he indicado, ha sido avalada en la doctrina para los supuestos en que el menor se traslada a España por nacionales españoles y residentes aquí ${ }^{27}$ en los mismos términos que el Dictamen 3/2016 de la Fiscalía General.

21. No se puede menos que discrepar pues si el argumento es que la adopción a constituir en España debe quedar sujeta a ley española como ley única (ex. art. 18 LAI 2017), obviando el mandato del artículo 19.4 LAI 2007 que es una norma imperativa dirigida a las autoridades ("se denegará la constitución de la adopción...) y justificado en aras del interés del menor, habría que preguntarse entonces para qué se introdujo en 2015 el artículo 19.4 LAI y en general, cuál es la función de una prohibición legal expresamente dirigida a la autoridad interviniente en la constitución. No creo que el significado y alcance de una prohibición dirigida a las autoridades eventualmente competentes sea cuestión discutible: se habilita su intervención en la constitución de la adopción dentro de unos parámetros legales. Por otra parte, la norma cumple o debiera cumplir una función disuasoria de ciertos comportamientos, y en este sentido debieran tomar nota abogados y asesores en adopción internacional desaconsejando la constitución de kafalas como antesala a la adopción.

22. Podrá objetarse que dotar al artículo 19.4 de ese significado es un argumento formal. Y lo es, si, junto a otro argumento formal y no menos relevante: la prohibición obedece asimismo a una finalidad del Derecho internacional privado y es la función de asegurar la continuidad de las relaciones jurídicas. La constitución de la adopción en España previa kafala en el extranjero, supondría la afirmación de dos estados civiles de muy distintos efectos que en el medio o largo plazo pueden chocar: establecimiento de un vínculo de filiación por la adopción, habiendo familiares afectados en el país de origen y cuyo consentimiento no se ha considerado. El desconocimiento o la prohibición de la adopción en el país de origen del adoptado conducirá al no reconocimiento de la constituida en España, un supuesto típico de situación claudicante que persigue el artículo 19.4 LAI, como se desprende de la Exposición de motivos. En último término, entiendo que el interés del menor no cristaliza prioritariamente en el establecimiento de la filiación adoptiva (favor adoptionis), pues de modo inmediato dicho interés se satisface correctamente si el menor es acogido, guardado, educado, protegido en el marco de otras instituciones que lo posibilitan como el acogimiento familiar.

\footnotetext{
214; Sobre la cuestión política subyacente a la prohibición C.I. Cordero Álvarez, “Adopción en Europa...”, cit. p.472; E. RODRIGUEZ PINEAU, "La protección en España de menores cuya ley nacional prohíbe la adopción...”, cit. p. 407.

${ }^{25}$ Auto AP de Palma de Mallorca, Sección cuarta, de 25 de octubre 2017 (ECLI:ES:APIB:2017:315 A)

${ }^{26}$ No lo he consultado directamente sino a través del análisis de M.J. SÁnchez CANo, "Adopción en España de menores en situación de Kafala y ley nacional del adoptando", cit., espec. p. 941.

${ }^{27}$ Cf. M.J. SÁnchez CANo, “Adopción en España de menores en situación de Kafala y ley nacional del adoptando”, cit.p. 942.
} 


\section{Sobre la posibilidad de constituir un acogimiento familiar permanente.}

23. En fin, la demandante en instancia solicitaba, subsidiariamente y de no acordarse la adopción, un acogimiento familiar permanente. Pretensión que estima la Audiencia Provincial “...en interés del menor... conforme a lo previsto por el artículo 173 bis c), al aconsejarlo las circunstancias del menor y su familia, con todos los efectos y obligaciones previstos en el art. 173.1 del referido texto legal" ${ }^{28}$, revocando el Auto del Juzgado de Instancia en este punto, que había rechazado esta segunda pretensión.

24. Admitido que la kafala no se asimila a la adopción en el ordenamiento español sino que se adecúa dentro de éste, equiparándose a la tutela o a un acogimiento familiar (art. 34 LAI 2007), el juzgador admite el acogimiento familiar permanente. En este sentido se razona correctamente en términos de equivalencia (art. 34.1.1 $1^{\circ}$ LAI 2007) o de calificación por la función que desempeña la institución extranjera cuyos efectos se pretenden hacer valer en España, determinando que la kafala cumple una función similar a la del acogimiento familiar, "que produce la plena participación del menor en la vida familiar e impone en quien lo recibe las obligaciones de velar por él, tenerlo en su compañía, alimentarlo, educarlo y procurarle una formación integral...pero que ni crea vínculos nuevos de filiación, ni rompe los anteriores, ni priva de la patria potestad a los padres".

25. Omite en cambio el examen de los demás requisitos exigidos para el reconocimiento ( $e x$ art. 34.1 LAI 2007). Aunque es evidente por el sustrato fáctico que no había infracción del orden público español (art. 34.1.3 ${ }^{\circ}$ LAI 2007) y que presumiblemente el documento extranjero habrá observado las exigencias relativas a la autenticidad (art. $341.4^{\circ}$ LAI 2007), habría sido interesante verificar cómo se efectúa el contraste de los vínculos razonables con el estado extranjero para asegurar la competencia de la autoridad extranjera en origen (art. 34.1.2 ${ }^{\circ}$ LAI 2007); no ha sido así, pero es la única omisión reseñable. Como tampoco se indica la posibilidad de proceder a un reconocimiento registral de carácter incidental ante el encargado del Registro civil conforme al artículo 11 de la Ley 15/2015, sobre Jurisdicción voluntaria, de tal modo que el encargado pueda proceder a la anotación calificando bien como acogimiento, bien como tutela, una vez inscrito el nacimiento del menor ${ }^{29}$

26. En suma, como en tantas otras ocasiones, hay que felicitar al juzgador por resolver alineado con la ley, su finalidad y la interpretación que de esta cuestión han dado el Tribunal Europeo de Derechos Humanos y el Tribunal de Justicia de la UE.

\footnotetext{
${ }^{28} \mathrm{FJ} 3^{\circ}$

${ }^{29}$ Cf. S. Adroher Biosca, "La kafala islámica...”, cit. pp. 210-211
} 